\title{
Case Reports: More than Anectodal Evidence
}

\section{Ugo Marone*}

Department of Surgery "Melanoma - Soft Tissues - Head \& Neck - Skin Cancers", National Cancer Institute of Naples, Italy

\section{Case reports represent the oldest levels of evidence in medical science}

In medical history most of scientific articles have been done in form of case reports: the first description of melanoma was done by Norris in 1820, who reported the history of a patient referred as a case of "fungoid disease"; Christian Barnard described the world's first heart transplant as a case report, and many examples could be done [1-2].

Case reports consist of information about symptoms, signs, diagnosis, treatment and follow-up of an individual patient or of a little series of patients, usually with description of a typical or new occurrence.

The value of case reports is that they represent a great manner to share notices about an usual or unique conditions encountered by physicians and surgeons, presenting an event that is new or clinically educational, describing a new disease or giving insight into the pathogenesis of a disease, a new complication of a treatment or a new and practical approach to the diagnosis or management of a disease. Other advantage of case reports is they can be published quickly in comparison to randomized control trials, making them to be a kind of rapid short statement between clinicians.

In recent years, randomized clinical trials, systematic reviews and meta-analyses have represented the gold standard in medical literature, so case reports are often not published by many journals, to preserve their impact factor. It's true that randomized clinical trials can give us a statistical answer for very narrow clinical questions. But case reports can detail many different aspects of the patient's medical situation missed or undetectable by clinical studies, specifically including patient history, physical examination, psycho-social aspects, follow-up. Recently, some authors demonstrated that case reports and case series can have substantial impact on the literature, and for many treatments they are the only available evidence. Therefore they suggested that a guideline for case reporting should be developed to improve their quality [3].

Most case reports should be on one of these topics [4]:

1. An unexpected association between diseases or symptoms

2. An unexpected event in the course of observing or treating a patient

3. Findings that shed new light on the possible pathogenesis of a disease or an adverse effect
4. Unique or rare features of a disease

5. Unique therapeutic approaches

6. A positional or quantitative variation of the anatomical structures.

Actually many journals have reconsidered their policy towards case reports and there has been a recent trend in new journals publishing exclusively case reports, like Journal of Clinical Case Reports (JCCR).

JCCR will only published case reports which are clinically interesting, original and educational with rapid turn-around time possible for reviewing, publishing and for disseminate the articles freely for research, teaching and reference purpose. JCCR-open access will give a worldwide audience larger, and probably increases the visibility and impact of published work. Types of cases we will be interested in include: rare diseases novel diagnostic procedures, novel treatment and unusual presentation of more common disease/injury.

Case reports can represent more than anecdotal evidence. With this editorial I can line up my point of view with Vandenbroucke [4] in defensing of this form of medical evidence remarking his words: "They permit discovery of new diseases and unexpected effects (adverse or beneficial) as well as the study of mechanisms, and they play an important role in medical education. Case reports and series have a high sensitivity for detecting novelty and therefore remain one of the cornerstones of medical progress; they provide many new ideas in medicine".

Furthermore, I welcome submission of interesting and relevant cases to the Journal of Clinical Case Reports, encouraging submission about first description, or report of an already described but rare, disease, syndrome, diagnostic test, surgical procedure.

\section{References}

1. Norris W (1820) A Case of Fungoid Disease. Edinburgh Med and Surg J 16 562-565.

2. Barnard CN (1967) The operation. A human cardiac transplant: an interim report of a successful operation performed at Groote Schuur Hospital, Cape Town. S Afr Med J 41: 1271-1274.

3. Albrecht J, Meves A, Bigby M (2005) Case reports and case series from Lance had significant impact on medical literature. J Clin Epidemiol 58: 1227-1232.

4. Vandenbroucke JP (2001) In defense of case reports and case series. Ann Intern Med 134: 330-334.

*Corresponding author: Ugo Marone, National Cancer Institute, Via Mariano Semmola, 80131, Naples, Italy, Tel: +390815903460; Fax: +390815903810; E-mail: dott.marone@virgilio.it

Received January 09, 2011; Accepted January 18, 2012; Published January 27 2012

Citation: Marone U (2012) Case Reports: More than Anectodal Evidence. J Clinic Case Reports 2:e111. doi:10.4172/2165-7920.1000e111

Copyright: (c) 2012 Marone U. This is an open-access article distributed under the terms of the Creative Commons Attribution License, which permits unrestricted use, distribution, and reproduction in any medium, provided the original author and source are credited. 